Journal of Current and Advance Medical Research

January 2017, Vol. 4, No. 1, pp. 23-26

http://www.banglajol.info/index.php/JCAMR

ISSN (Print) 2313-447X

Original Article

OPEN ACCESS

\title{
Socio-demographic Factors Associated with Emergency Caesarean Section Cases admitted at Tertiary Care Hospital in Dhaka City
}

\author{
Rifat Sultana ${ }^{1}$, Dewan Shahida Banu², Mahmuda Khatun ${ }^{3}$, Fatima Dolon ${ }^{4}$, Mahmuda Nahar ${ }^{5}$, \\ Nasrin Sultana ${ }^{6}$
}

\begin{abstract}
${ }^{1}$ Assistant Professor, Department of Gynaecology \& Obstetrics, Shaheed Taj Uddin Ahmad Medical College, Gajipur, Bangladesh; ${ }^{2}$ Assistant Professor, Department of Gynaecology \& Obstetrics, Shaheed Taj Uddin Ahmad Medical College, Gajipur, Bangladesh; ${ }^{3}$ Assistant Professor, Department of Gynaecology \& Obstetrics, Shaheed Taj Uddin Ahmad Medical College, Gajipur, Bangladesh; ${ }^{4}$ Senior Consultant (Gynaecology \& Obstetrics), Shaheed Tajuddi n Ahmad Medical College \& Hospital, Gazipur, Bangladesh; ${ }^{5}$ Junior Consultant (Gynaecology \& Obstetrics), Shaheed Tajuddin Ahmad Medical College \& Hospital, Gazipur, Bangladesh; ${ }^{6}$ Assistant Professor, Department of Community Medicine, Shaheed Taj Uddin Ahmad Medical College, Gajipur, Bangladesh
\end{abstract}

[Reviewed: 30 January 2016; Accepted on: 1 March 2016; Published on: 1 January 2017]

\section{Abstract}

Background: Socio-demographic factors are related with the need of emergency obstetric care. Objectives: The purpose of the present study was to see the socio-demographic characteristics of emergency caesarean section. Methodology: This cross-sectional of study was conducted in the Department of Obstetrics and Gynaecology at Dhaka Medical College, Dhaka from the duration July 2006 to December 2006 for a period of six (6) months. The pregnant women underwent emergency caesarean section admitted at Dhaka Medical College Hospital during the mentioned period of the study were my study population. The cases were selected from the patients who got admitted at obstetrics ward of DMCH with an indication of emergency caesarean section with stable general condition at that moment. Every 10th patient was selected for the study. Data has been collected after taking written consent from the patients as per consent form. Then a thorough history, clinical examination was done and information were collected. Intraoperative complications such as haemorrhage, cardiac arrest were noted. Result: The study was performed on 100 cases of which 35(35.0\%) emergency caesarean section cases belonged to the age group of 20 to 24 years and $56.0 \%$ were from lower socio economic class. Among them $42.0 \%$ of the cases of emergency caesarean section had education SSC and above level; furthermore $12.0 \%$ were illiterate. In addition $92.0 \%$ cases were house wife. Conclusion: In conclusion young house wives from lower socio economic status are mostly underwent emergency caesarean section. [Journal of Current and Advance Medical Research 2017;4(1):23-26]

Keywords: caesarean section; Socio-demographic factors; age difference; emergency

Correspondence: Dr. Rifat Sultana, Assistant Professor, Department of Gynaecology \& Obstetrics, Shaheed Taj Uddin Ahmad Medical College, Gajipur, Bangladesh; Email: dr.rifat.sultana@ gmail.com; Cell no.: +8801711539801

Cite this article as: Sultana R, Banu DS, Khatun M, Dolon F, Nahar M, Sultana N. Socio-demographic Factors Associated with Emergency Caesarean Section Cases admitted at Tertiary Care Hospital in Dhaka City. Journal of Current and Advance Medical Research 2017;4(1):23-26

Conflict of Interest: The authors of this paper have declared that there is no conflict of interest to any of the authors.

Funding: This study has been performed without any funding from outside else.

Contributions to authors: Sultana R, Banu DS \& Khatun M, have contributed in protocol preparation up to surgical procedures as well as the report writing; Dolon F \& Nahar M Sultana N have written the manuscript and have revised the manuscript.

Copyright: (92017 Sultana et al. Published by Journal of Current and Advance Medical Research. This article is published under the Creative Commons CC BY-NC License (https://creativecommons.org/licenses/by-nc/4.0/). This license permits use, distribution and reproduction in any medium, provided the original work is properly cited, and is not used for commercial purposes. 


\section{Introduction}

Promotion of maternal and child health has been one of the most important components of the Family Welfare Program of the Government of Bangladesh since its independence ${ }^{1}$. Also the National Population Policy reiterates the government's commitment to the safe motherhood program within the wider context of reproductive health ${ }^{2}$.

However, the maternal mortality ratio in Bangladesh is one of the highest in the world, despite the presence of relevant policy and programmatic initiatives ${ }^{3}$. Moreover, the estimated lifetime risk of dying from pregnancy and child birth-related causes is about 100 times higher than that in developed countries ${ }^{1}$. The coverage of institutional delivery and delivery assistance by health professional were lower in rural areas where socio-economic status is lower than that of the urban areas. Such a scenario in urban slums is considered to be almost the same as that for the rural areas. Studies found that women with lower socioeconomic status often do not avail the existing reproductive health care services, particularly delivery care services.

Both socioeconomic and demographic factors, however, have been shown to have a particularly greater influence on the use of health care services (4- 8). Also, in studies of preventive and curative services it was often found that the use of health services is related to the availability, quality and cost of services, as well as social structure, health beliefs and personal characteristics of the users(912). Thus, considering such issues an attempt has been made in this study to identify the socioeconomic determinants of institutional delivery as well as delivery assistance from health professional.

\section{Methodology}

This cross sectional study was conducted in the Department of Gynaecology and Obstetrics at Dhaka Medical College Hospital, Dhaka the busiest tertiary care hospital in Bangladesh, during the period from July 2006 to December 2006 for a period of six (6) months. The patients underwent emergency caesarean section for any indication during the mentioned period of study was selected as study population. The cases were selected by random sampling from the patients with an indication of emergency caesarean section but with stable general condition at that moment. Every 10th patient was selected for the study. Data were collected after taking written consent from the properly selected patients. At first, thorough history as per prepared questionnaire, then clinical examination was done and information was collected. All relevant clinical information of the cases was recorded systematically in the predesigned clinical data sheet. Data were checked, verified and complied by computer; analysis was done by using SPSS and the results were displayed in tables and diagrams.

\section{Result}

A total number of 100 patients were recruited for this study. The most of the emergency caesarean section cases were performed among the age group of 20 to 24 years which was $35(35.0 \%)$ cases followed by 25 to 29 years, 30 to 34 years and less than 20 years of age group which were $31(310 . \%)$ cases, 24(24.0\%) cases and 6(6.0\%) cases respectively (Table 1$)$.

\section{Table 1: Distribution of Cases According to} Their Age $(n=100)$

\begin{tabular}{|l|c|c|}
\hline Age Group & Frequency & Percentage \\
\hline Less Than 24 Years & 41 & 41.0 \\
\hline More than 24 Years & 59 & 59.0 \\
\hline Total & $\mathbf{1 0 0}$ & $\mathbf{1 0 0 . 0}$ \\
\hline
\end{tabular}

Majority of the patients (56\%) were from lower socio economic group; however, middle and upper class groups were $27 \%$ cases and $17 \%$ cases respectively (Table 2 ).

Table 2: Distribution of Cases According to Their Socio-economic Status $(n=100)$

\begin{tabular}{|l|c|c|}
\hline $\begin{array}{l}\text { Socio-economic } \\
\text { group }\end{array}$ & Frequency & Percentage \\
\hline Lower Class & 56 & 56.0 \\
\hline Middle Class & 27 & 27.0 \\
\hline Upper Class & 17 & 17.0 \\
\hline Total & $\mathbf{1 0 0}$ & $\mathbf{1 0 0 . 0}$ \\
\hline
\end{tabular}

Among the 100 cases $42.0 \%$ had emergency caesarean section who were having education SSC above level $13 \%$ and $17 \%$ were from HSC and degree equivalent, $16 \%$ had primary education and only a few $12 \%$ were illiterate (Table 3 ). Among the 100 cases $92 \%$ had emergency caesarean section were housewife while $8 \%$ were service holder and others (Table 4). 
Table 3: Distribution of Cases According to Educational Status $(n=100)$

\begin{tabular}{|l|c|c|}
\hline Educational Status & Frequency & Percentage \\
\hline Illiterate & 12 & 12.0 \\
\hline Primary & 16 & 16.0 \\
\hline SSC & 42 & 42.0 \\
\hline HSC & 13 & 13.0 \\
\hline Degree \& above & 17 & 17.0 \\
\hline Total & $\mathbf{1 0 0}$ & $\mathbf{1 0 0 . 0}$ \\
\hline
\end{tabular}

\section{Discussion}

The lower institutional delivery and assisted by health professional generates a very relevant query: what are the factors that affects women to utilize institutional as well as assistance from health professional in slum areas where poor socioeconomic conditions prevail to a greater extent ${ }^{2}$. Worldwide, maternal mortality remains a major challenge to health systems. An estimated 358000 maternal deaths occurred globally in 2008 of which $99.0 \%$ were accounted for in developing countries ${ }^{4}$. Bangladesh is 1 of the 11 countries that contributed to $65 \%$ of that maternal mortality ${ }^{3}$. There are substantial socioeconomic disparities in access to professional delivery care in low and middle income countries.

\section{Table 4: Distribution of Study Population According to Occupation $(n=100)$}

\begin{tabular}{|l|c|c|}
\hline Educational Status & Frequency & Percentage \\
\hline Housewife & 92 & 92.0 \\
\hline $\begin{array}{l}\text { Service Holder \& } \\
\text { Others }\end{array}$ & 8 & 8.0 \\
\hline Total & $\mathbf{1 0 0}$ & $\mathbf{1 0 0 . 0}$ \\
\hline
\end{tabular}

The International Safe Motherhood Initiative made maternal mortality an international priority by the way of access to basic maternity care during pregnancy and delivery to all women ${ }^{4}$. One of the best way to do this is to make sure that women receive skilled care at delivery. Providing skilled care means ensuring that health professionals such as doctors, nurses or midwives can manage normal deliveries and treat the life-threatening complications of pregnancy and child birth. Therefore, skilled care at delivery or "safe delivery" has its greater significance in reducing sufferings of reproductive health system from women. Delivery performed by trained personnel with proper equipment and correct technique is the safest. So, safe delivery ensures that all deliveries are attended by persons with the right knowledge, skills, and equipment and also provide postpartum care to mother and baby ${ }^{5}$.

The incidence of caesarean section varies from country to country, hospital to hospital and community to community. In the past 20 years, the rate of caesarean section had steadily increased ${ }^{6}$. Every operative procedure has its own hazards. Caesarean section is also not free from them. The risk of maternal death from caesarean section is four to six times greater than that of vaginal delivery $^{7}$. But the improved safety of surgery with modern anesthetic techniques, availability of antibiotics, blood transfusion and intravenous fluid those have made caesarean section safer than they were. In emergency situation, caesarean section is done due to unforeseen complication arising either daring pregnancy or daring labour and acts as a life saving measure for both the mother and the fetus. Thus, it is necessary to bring all of these points in consideration along with the factors responsible for emergency caesarean section and outcome of this should be studied much more ${ }^{8}$. The incidence of caesarean section is gradually increasing in developing and also developed countries. The rate should be $7.0 \%$ in developed countries and less than $10.0 \%$ in developing countries. Minimum acceptable level as recommended in the guide line for monitoring progress in the reduction of maternal mortality, caesarean section as percentage of all births is not less than $5 \%$ cases and not more than $15.0 \%$ cases $^{9}$.

It has been found that more than half $(90 \%)$ of the cases were belonged to the age group of 20 to 34 years. These findings are similar to Petrou et $\mathrm{al}^{10}$. In this study it has been also found that $4.0 \%$ of cases belonged to more than 35 years. This is similar to Joll et $\mathrm{al}^{11}$ of St Mary's, Hospital in England and had shown that pregnant women with the age group of 35 to 40 years of old were at increased rate of gestational diabetics, placenta previa and thereby increased rate of emergency caesarean section. The age group is nearer with Tadesse et $\mathrm{al}^{12}$ which was $57.0 \%$ among 20 to 30 years of age group; however Banu and Rouf ${ }^{13}$ at different hospitals of Dhaka city have reported a $16.0 \%$ cases among more than 35 years of age group.

Hospital is the safe place to delivery. Many women living in developing country like Bangladesh have come to the hospital at terminal stage after giving trial for normal delivery ${ }^{14}$. In another study Begum et $\mathrm{al}^{15}$ have shown that women with primary and greater than primary education were significantly more likely to deliver at institute $(\mathrm{OR}=3.361$ and 5.784 respectively) and to deliver by health 
professional $(\mathrm{OR}=2.362$ and 6.479 respectively) compared to women with no education. Similarly, women's high level of knowledge on maternal health care services was found to have a significant influence only on institutional delivery $(\mathrm{OR}=4.527)$ in the same study ${ }^{15}$.

This study shows that more than half $(56.0 \%)$ of the patients were from lower socio economic class and three fourth $(70.0 \%)$ of the cases had educated of SSC and below. This study was carried out to identify the factors which influenced choice of place of delivery by pregnant women and to recommend ways to improve women's access to skilled attendants at delivery. A pre-tested questionnaire was administered by interviewers to women who had delivered within 3 months prior to date of data collection. The response rate was $75.5 \%$. Of the respondents, $52.9 \%$ delivered outside health institutions and $47.1 \%$ in health institutions ${ }^{16}$.

\section{Conclusion}

In conclusion lower socioeconomic and educational conditions increases the emergency caesarean section operations. In this study emergency caesarean section rate was higher due to lack of proper antenatal care, illiteracy and low socioeconomic status. Although apparently it creates a good impression over the higher status but as a matter of fact higher socioeconomic and educational status favors the repeated and proper antenatal checkup which help to detect high risk mothers for special care; thus decreases the emergency caesarean section rates to prevent the maternal and infant deaths as well as their morbidities.

\section{Reference}

1. National Institute of Population Research and Training (NIPORT). ORC Macro, John Hopkins University, ICDDR, B Bangladesh maternal health services and mortality survey 2001. Dhaka and Calverton, 2003
2. National Institute of Population Research and Training (NIPORT), Mitra and Associates, and Macro International. 2009. Bangladesh Demographic and Health Survey 2007. Dhaka, Bangladesh and Calverton, Maryland, USA: National Institute of Population Research and Training, Mitra and Associates, and Macro International.

3. World Health Organization, United Nations Children's Fund, United Nations Population Fund. Trends in Maternal Mortality: 1990-2008. Geneva, Switzerland: World Health Organization; 2010

4. Mahler H. The safe motherhood initiative: a call to action. Lancet 1987;1:668-670.

5. Wanjira C, Mwangi M, Mathenge E, Mbugua G, Ng'ang'a Z. Delivery practices and associated factors among mothers seeking child welfare services in selected health facilities in Nyandarua South District, Kenya. BMC Public Health 2011;11:360.

6. Royston E, Armstrong D. Preventing Maternal Deaths, World Health Organization, Geneva 1989:9-10

7. Ratnum SS, Rao KB, Arulkumarans P. Obstetrics and gynaecology for postgraduates, 2nd edition, Orient longman, Hyderabad, India. 1992;1(1):10-14;145-52

8. Azim AKMA, Salauddin AKM, Bari MA. A study of $\mathrm{MCH}$ service among the slum dwellers of Dhaka city. Bangladesh Journal of Obstet Gynaecol 2000:15(1):10-14

9. A review of the emergency obstetric care functions of sedated facilities in Bangladesh, UNINICEF, 1993;10-12

10. Petrou S, Kuppek E, Vauses S, Marsh M. Clinical, Provider and sociodemographic determinates of the number of antenatal visits in England and Wales, Soe Scl Med, 2001;52(7):1123-34

11. Jolly M, Sebire N, Harris J, Robinson S, Regan L. The risks associated with pregnancy in women aged 35 years or order, Him Repord 2000:15(11):2433-37

12. Tadesse E, Adane M, Abiyou M. Caesarean Section deliveries at Tikur Anbessa Teaching Hospital, Eithiopia. East Afr Med J 1999;73(9):619-22

13. Banu RA, Rouf MA. A comparative study on Antenatal care practice among the pregnant women Admitted in different hospitals in Dhaka city. Northern Medical Journal 1995;4(2):52-57

14. Shorten A, Lewis DE, Shorten B, Trail of labour versus elective repeat caesarean section a cost effectiveness analysis, Aust Health Rebv 1998;(1):8-28

15. Begum H, Sayem AM, Nilufar N. Differentials in place of deliveryand delivery assistance in urban slum areas, Bangladesh. Journal of Family and Reproductive Health 2012;6(2):49-58

16. Onah HE, Ikeako LC, Iloabachie GC. Factors associated with the use of maternity services in Enugu, southeastern Nigeria. Social Science Medicine 2006;63(7):1870-78 